\title{
DIREITOS HUMANOS E CULTURA: A FRAGILIDADE DO DISCURSO UNIVERSALISTA NO CONTEXTO FRANCÊS
}

\author{
DERECHOS HUMANOS Y CULTURA: LA FRAGILIDAD DEL DISCURSO \\ UNIVERSALISTA EN EL CONTEXTO FRANCÉS
}

\author{
HUMAN RIGHTS AND CULTURE: THE FRAGILITY OF UNIVERSALIST SPEECH \\ IN FRENCH CONTEXT
}

\author{
Giovanna Lopes SOUZA ${ }^{1}$
}

RESUMO: Este artigo discute os conflitos culturais de significação ocasionados pela discriminação de bens mobilizada pela legislação francesa em relação ao islamismo ao sancionar a Lei 1192/2010, especificamente, objetivando o uso do véu integral pelas mulheres muçulmanas nos espaços públicos franceses. À luz de Marshall Sahlins, Mary Douglas e Paula Montero, será discutida a aplicabilidade de direitos universais frente a conflitos culturais no contexto em que a correlação de forças é assimétrica e passa por um processo arbitrário de globalização de valores ocidentais a partir da narrativa legal.

PALAVRAS-CHAVE: Antropologia. Direitos humanos. Identidade. Véu islâmico.

RESUMEN: Este artículo discute los conflictos culturales de significación ocasionados por la discriminación de bienes movilizada por la legislación francesa en relación al islamismo al sancionar la Ley 1192/2010, específicamente, objetivando el uso del velo integral por las mujeres musulmanas en espacios públicos franceses. Basado en Marshall Sahlins, Mary Douglas y Paula Montero, se discutirá la aplicabilidad de derechos universales frente a conflictos culturales en el contexto que la correlación de fuerzas es asimétrica y pasa por un proceso arbitrario de globalización de valores occidentales a partir de la narrativa legal.

PALABRAS CLAVE: Antropología. Derechos humanos. Identidad. Velo islámico.

ABSTRACT: This article discusses the cultural conflicts of meaning caused by the discrimination of assets mobilized by French legislation on Islamism by sanctioning Law 1192/2010, specifically, aiming at the use of the integral veil by Muslim women in French public spaces. Based in Marshall Sahlins, Mary Douglas and Paula Montero, the applicability of universal rights on cultural conflicts will be discussed in the context in which the correlation of forces is asymmetric and goes through an arbitrary process of globalization of western values from the legal narrative.

KEYWORDS: Anthropology. Human rights. Identity. Islamic veil.

${ }^{1}$ Universidade Estadual Paulista (UNESP), Araraquara - SP - Brasil. Graduanda em Ciências Sociais. ORCID: <https://orcid.org/0000-0002-8912-1794>.E-mail: giovannalopessouza@gmail.com 


\section{Introdução}

Os conjuntos de valores que representam grupos sociais não são um quadro consolidado, passam por uma revisão e reavaliação cotidiana: são processos históricos que alteram seu curso na ação, estando sujeitos a ressignificações. Contudo, entre mudanças e permanências, a realidade é constituída individual e coletivamente através deste idioma cultural apreendido. As identidades e coletividades geradas pelas diversas formas de experiência social coexistem nas cidades, estados e países, buscando articular horizontes culturais diversos através da política e do direito, ancorando-se nas liberdades democráticas para sua expressão e nos direitos humanos universais para sua proteção. No entanto, percebe-se que “[...] apenas uma parcela minoritária da população mundial possui condições de se beneficiar das normas e regulações jurídicas. A maioria da humanidade encontra-se à parte do sistema jurídico, contemplando-o, sem, contudo, poder contar efetivamente com a proteção da lei” (PINHERO apud UNDP, 2008, p. 16). Assim, a ideia de universalidade desses direitos esbarra na estrutura econômica e social quando posta em prática, demonstrando sua limitada abrangência.

Em meio à trama de interpretações e reflexões sobre o papel dos Direitos Humanos frente à cultura no mundo globalizado, este ensaio, que consiste em uma revisão bibliográfica. Inspirada principalmente por Marshall Sahlins, Mary Douglas e Paula Montero, este trabalho adentrará nos conflitos culturais de significação ocasionados a partir da discriminação de bens mobilizada pela legislação francesa frente ao islamismo, especificamente, às mulheres muçulmanas. A propósito de estudo de caso e por oferecer uma conjuntura onde várias dimensões desse conflito são suscitadas, analisaremos a Lei 1192/2010 da França. Tal lei, perante multa e penas alternativas, coibiu a utilização, em espaços públicos, de vestes que dissimulam e ocultam o rosto, incluindo de um capuz e um capacete à Burca e ao Niqab, em razão de que a impossibilidade de identificar o rosto causa insegurança social e, portanto, fragiliza a ordem pública.

Dessa forma, traremos na discussão sobre a aplicabilidade de direitos universais frente a conflitos culturais no contexto em que a correlação de forças é assimétrica e passa por um processo arbitrário de globalização de valores ocidentais, a partir da narrativa da lei, que conta com a legitimidade do uso do aparato do poder político e jurídico. A instrumentalização e a estigmatização de certos bens torna-se uma estratégia para distinguir e marginalizar grupos sociais a partir da ambiguidade do texto legal bem como da negligência da ação pública. Portando, nesse contexto, a universalidade perde sua abrangência e passa a representar um universo cultural e político específico e homogeneizante. 


\section{Democracia e Cultura}

A democracia é considerada por diversos países e culturas como um valor universal, ou seja, o modelo político melhor desenvolvido para reger a relação entre o Estado e a sociedade a fim de expandir a participação popular nas tomadas de decisão de cunho público e de promover a garantia direitos fundamentais. "O que é valor universal não são as formas concretas que a democracia assume institucionalmente em dado momento, mas o processo pelo qual a política se socializa e, progressivamente propõe novas formas de socialização do poder" (COUTINHO, 2002). Contudo, a democracia tem uma estreita participação quando associada ao capitalismo em um contexto não igualitário de desigualdades sociais e econômicas, isto é, um cenário de acesso seletivo e desproporcional a políticas públicas, representação jurídica, conquista de direitos. "A democracia, no entanto, não é uma panacéia capaz de, por si só, eliminar o autoritarismo e prevenir violações de direitos humanos, como pudemos aprender à chaud na América Latina" (PINHEIRO, 2008, p. 78).

O período de construção e solidificação dos Estados Nacionais, no qual se travou uma disputa de laços de pertencimento, introduziu noções como a cidadania e a sociedade civil, contrapostas a outros elos comunais como religiosos e étnicos. Em nome da ideologia da identidade nacional e da territorialidade, pode-se dizer que as sociedades sofreram com o efeito homogeneizador contra particularidades locais ou minoritárias. Entretanto, a dimensão e efetividade dessa homogeneização são muitas vezes superestimadas, visto que a história não é escrita por seres passivos, mas por agentes interessados e que atribuem significados diversos às mudanças sofridas. "O sistema mundial não é uma física de relações proporcionais entre impactos econômicos e reações culturais. Os efeitos específicos das forças materiais-globais dependem das várias maneiras pelas quais elas são mediadas nos esquemas culturais locais." (SAHLINS, 1988, p. 446) Desse modo, o conflito de identidades traçado na política segue constituindo um dos dilemas mais caros à democracia: a conciliação entre liberdade e igualdade.

Apesar de o capitalismo marcar seu início como um sistema transnacional, é no contexto da globalização que este dilema é amplificado e largamente debatido. A mundialização da economia e da cultura enquanto uma rede complexa de intercâmbio de ideias, valores, pessoas e objetos é responsável pelo constante choque entre a orientação dos interesses nacionais, particulares e globais. É nesse contexto em que identidades são ora multiplicadas e ora radicalizadas, em que o trabalho do Estado em busca de uma vontade que represente os 
interesses da maioria passa por um profundo desentendimento, visto que com a crise deste Estado Nacional o sentimento de cidadania retraiu-se, por um lado fragmentando-se em grupos locais e por outro expandido os laços de pertencimento social ao nível cosmopolita. E nessa trama em que a cultura se torna passível de instrumentalização no meio político e jurídico, observaremos o impacto de convenções mundiais como a Declaração Universal dos Direitos Humanos (1948) em diálogo com legislações locais frente a conflitos de cunhos religiosos, étnicos e culturais.

\section{A dimensão simbólica dos bens e representação}

Adentrando na situação da cultura no contexto democrático e globalizado e a fim de delimitar o foco desta análise, evidenciaremos uma das diversas expressões de representação cultural: a produção e utilização bens. "Em vez de supor que os bens sejam em primeiro lugar necessários à subsistência e à exibição competitiva, suponhamos que sejam necessários para dar visibilidade e estabilidade às categorias da cultura" (DOUGLAS, 2009, p. 105). Sendo estes a parte visível da cultura, são responsáveis por demarcar diferenças e semelhanças estéticas, étnicas, ideológicas e religiosas conforme a identidade que representam, passando por relações hierárquicas de acordo com o esquema simbólico e as relações de poder nas quais estão inseridos.

Ultrapassando a lógica utilitarista que trata dos objetos em função de sua razão prática, pensar nestes como significantes da vida social, que definidos pelas pessoas também possuem papel ativo ao defini-las através de significados tomados em cada contexto, é por consequência pensá-los enquanto tradutores de discursos e valores. Olhar para a dimensão simbólica dos bens é perceber a expressão material das formas de estar no mundo e as relações significativas que são construídas através delas, entre pessoas e entre grupos, demarcando relações positivas de pertencimentos e exclusões que comunicam com o seu contexto. "Isto vai ao encontro do que é proposto por Leach (1990), quando afirma que a essência do comportamento simbólico público é ser um meio de comunicação" (FERREIRA, 2013, p. 191).

Isto posto, ressaltaremos o exemplo particular do uso do véu islâmico pelas mulheres muçulmanas e alguns de seus significados suscitados. O uso do véu é, além de uma tradição cultural que remente às antigas culturas indo-europeias, também uma orientação mencionada em algumas suratas do Alcorão que dizem respeito à demonstrar modéstia e humildade da 
mulher muçulmana, bem como é indicado para a sua proteção, nos espaços públicos, do olhar ou violência por parte dos homens.

Dize também às crentes que recatem seus olhares, conservem seus pudores e não mostrem seus encantos naturais, além do imprescindível; que cubram o rosto com os seus véus e não mostrem seus encantos a não ser a seus esposos, seus pais, seus sogros, seus filhos, seus enteados, seus irmãos, seus sobrinhos e sobrinhas, às mulheres crentes, suas servas, seus criados não púberes ou crianças que não discernem sobre a nudez das mulheres; que não agitem seus pés para que se descerre o que oculta seus encantos. Ó crentes, voltai-vos todos, arrependidos, a Deus, a fim de que triunfeis (ALCORÃO, surata 24 , versículo 31 )

$[\ldots]$

Ó profeta, dize a tuas esposas, a tuas filhas e às mulheres dos crentes que, quando saírem, cubram-se com seus véus; isso é mais conveniente para que se distingam das demais e não sejam molestadas; atenta para o fato de que Deus é Indulgente, Misericordiosíssimo (ALCORÃO, surata 33, versículo 59).

Os diferentes tipos de véu são utilizados pelas mulheres de acordo com a sua orientação religiosa específica, sua fé e cultura, seu status social e diante de quem estas julgarem apropriado. "Cobrir o rosto em determinados contextos significa maneiras de demonstrar autorespeito e posição social.” (FERREIRA, 2013, p. 188) Ou seja, trata-se de um bem que está inserido em um amplo e consistente esquema simbólico e que tem relação direta com a moralidade e a dignidade das mulheres que fazem seu uso, sendo parte do seu estilo de vida. Dessa forma, apesar da religião ser um campo desterritorializado, compreende-se que o uso do véu representa uma fronteira simbólica a qual o significado foi tomado por narrativas espetacularizadas sobre o islã e o papel da mulher.

Segundo a pesquisa realizada pelo Pew Research Center, em 2010 na França, de seus 65 milhões de cidadãos, 7,5\% da população era muçulmana, em torno de cinco milhões de pessoas, destas, duas mil são mulheres que fazem o uso da Burca ou Niqab. Mesmo sendo o país europeu com maior número de refugiados islâmicos, essa quantidade de mulheres demonstra ser minoritária. Contando com uma maioria católica, os franceses frente à recente crise dos refugiados e o crescente medo do terrorismo ora amplificado pela narrativa midiática e ora vivenciado na realidade, colaboraram para atribuir ao véu significados pejorativos, xenofóbicos e islamofóbicos. Por outro lado, a construção da imagem do lenço islâmico também é fundada no antigo discurso feminista europeu, o qual associa a utilização do véu com a suposta falta de agência e autonomia da mulher muçulmana, em comparação à cultura ocidental na qual as mulheres, em tese, teriam mais autonomia para decidir sobre as suas vestimentas e seu estilo de vida. 


\begin{abstract}
Dois pontos emergem dessa discussão básica dos significados do uso do véu no mundo muçulmano contemporâneo. Primeiro, precisamos trabalhar contra a interpretação reducionista do véu como a quinta-essência dos sinais da falta de liberdade das mulheres, mesmo que nos oponhamos à imposição estatal dessa forma, como no Irã ou com o Talibã [...] O que significa a liberdade se aceitarmos a premissa fundamental de que os humanos são seres sociais, sempre criados em certos contextos sociais e históricos e pertencentes a comunidades particulares que dão forma a seus desejos e entendimentos do mundo? Não é uma grande violação aos entendimentos próprios das mulheres do que elas estão fazendo simplesmente denunciar a burca como uma imposição medieval? Segundo, devemos tomar cuidado para não reduzir as diversas situações e atitudes de milhões de mulheres muçulmanas para uma única peça de roupa (ABU-LUGHOD, 2012, p. 459-460).
\end{abstract}

Assim, existe uma ausência de interseccionalidade no feminismo ancorado na onda dos anos 1960, visto que colocar a mulher branca ocidental como centro dessa epistemologia é negligenciar que o desejo e a ideia de liberdade são histórica e culturalmente situados, não são mulheres com vivências idênticas e, portanto, não carregam demandas, categorias e reflexões idênticas.

\title{
A proibição do véu islâmico na França
}

Sob o princípio da laicidade, a partir de 2004 ocorreu uma movimentação no parlamento francês com fins de coibir a utilização do véu islâmico em algumas repartições públicas. A princípio, em 2004, a proibição contida na Lei de $n^{\circ} 228$ tratava de tolher a utilização de signos religiosos nas escolas e liceus, o que na prática significou que alunas, professoras e funcionárias públicas ficaram impedidas do uso de todos os tipos véu islâmico, não apenas o que cobre integralmente o rosto (Burca e Niqab).

Em 2009, após declarações do então presidente da república Nicolas Sarcozy, adentraram mais dois argumentos no debate a favor da ampliação do espectro da proibição: o de que a utilização do véu integral representaria insegurança social no tocante à identificação das pessoas em locais públicos e; novamente, figurar um atentado a igualdade de gênero, visto que a utilização deste sendo obrigatória apenas para as mulheres restringiria a sua liberdade em relação aos homens, a si e a sociedade.

O crescimento da adesão a esse ponto de vista pela sociedade civil e pelos políticos resultou na adoção da Lei 1192/2010, aprovada por imensa maioria em uma câmara constituída majoritariamente por homens, brancos e católicos. Entrando em vigor em 2011, a lei que em seu artigo $1^{\circ}$ interdita o uso, nos espaços públicos, de vestes que se destinem a dissimular o rosto, em seu artigo $3^{\circ}$ também prevê um Curso de Cidadania Francesa conforme o artigo $8^{\circ}$ do 
Código Penal além de multa e prisão para os perpetradores do uso. Ou seja, destas vestes que cobrem o rosto, estão inclusas de capacetes e capuzes à Burca e ao Niqab.

Retomando a discussão a respeito dos bens, acredito ser oportuna a reflexão acerca do significado dos objetos contemplados por essa medida, afinal capuzes, capacetes, a Burca e o Niqab configuram usos práticos e simbólicos diferentes entre si. Enquanto os dois primeiros relacionam-se com sua utilidade, para pilotar uma moto ou proteger-se da chuva, a utilização do véu islâmico escapa à razão prático-instrumental e situa-se no campo simbólico e religioso. Como vimos, o uso véu trata da identidade cultural, dignidade, respeito e proteção das mulheres muçulmanas, bem como é intrínseca a sua representação e expressão da fé islâmica. Contudo, fora da sua comunidade de linguagem, seu significado social externo é marcado por uma disputa de narrativa política, midiática e social que muitas vezes caminha em vias associar a religião islâmica ao terrorismo e ao autoritarismo. Nesse caso, o véu seria um representante da submissão feminina e ausência de liberdade nessa religião árabe, uma violência simbólica cometida contra as mulheres e contra os valores seculares da República Francesa. Em contraposição, as mulheres muçulmanas que se colocaram refratárias à lei de 2011 argumentam que a laicidade consiste em assegurar o direito a crença e a manifestação de todas as religiões. E que, pelo contrário, a ausência de liberdade e o autoritarismo residem em desrespeitar e coibir sua manifestação religiosa, e por consequência, seu direito de ir e vir.

\section{Direitos Humanos e universalidade}

Em 2018, a Organização das Nações Unidas (ONU) condenou a proibição do uso do véu integral islâmico na França. Reforçou o argumento já utilizado pelas feministas muçulmanas, declarando que esta lei fere os direitos humanos universais ao restringir o direito à liberdade religiosa como consta no artigo $18^{\circ}$ da Declaração Universal dos Direitos Humanos (DUDH):

Toda a pessoa tem direito à liberdade de pensamento, de consciência e de religião; este direito implica a liberdade de mudar de religião ou de convicção, assim como a liberdade de manifestar a religião ou convicção, sozinho ou em comum, tanto em público como em privado, pelo ensino, pela prática, pelo culto e pelos ritos (ONU, 1948).

Com a lei vigorando mediante esse cenário, é apropriado refletir sobre qual é o sujeito em questão dos Diretos Humanos e o quão universais estes realmente são. Neste caminho, o dilema democrático sobre conciliar horizontes culturais particulares recorre à utilização de um 
sujeito universal abstrato com necessidades semelhantes, mas que na materialidade representa apenas uma pequena parcela social que detém o poder político e econômico e para quem é conveniente a proibição de bens, de religiões e consequentemente de pessoas. Os esquemas simbólicos são responsáveis pela atribuição de valores para as coisas, ideias e corpos, e colocando essa lei em confronto com a DUDH. Percebe-se que a ideia universal sobre a liberdade religiosa é seletiva na prática, utilizando de valores mobilizados pela ideologia majoritária francesa para marginalizar um grupo a partir da proibição de um bem religioso de uso obrigatório. "É importante também perceber a importância pedagógica do discurso legal que, por sua simples circulação, é capaz de inaugurar novos estilos de moralidade e desenvolver sensibilidades éticas desconhecidas" (SEGATO, 2006, p. 219).

Dessa forma, a proibição do véu integral em nome da laicidade e da liberdade é um contrassenso. Primeiro, porque o princípio da laicidade diz respeito à coexistência pacífica entre religiões, utilizá-lo com fins de coibir uma manifestação religiosa através de uma manobra discursiva generalizante sobre os bens despendidos por essa crença faz com que a aplicabilidade dessa lei tenha um alvo único, delimitado e minoritário. Segundo, porque a liberdade salvacionista ostentada pelos parlamentares franceses é eurocentrada, desconsiderando na prática a diversidade das noções de liberdade bem como a agência e autonomia feminina. A suposta salvação das mulheres muçulmanas contra o machismo deu-se sem sua consulta ou participação, criando em nome da liberdade, outro aparelho repressivo. Dessa forma, a Lei 1192/2010 pode ser colocada enquanto uma contínua tentativa de homogeneização cultural em território francês, obstruindo qualquer confiança no vigor de uma cidadania diversa e participativa.

\section{Considerações Finais}

A causa e os efeitos da lei francesa de 2010 abordados neste ensaio oferecem um ensejo para interpretar a conjuntura complexa que enfrentam os Estados e a sociedade em medida de direitos, igualdade e liberdade. Os Estados Nacionais em formação com suas tentativas de homogeneização cultural falharam em abolir do mundo a diversidade e a diferença. Partindo do pressuposto que cultura é significação, torna-se impossível que haja a destruição completa de diversidades locais, visto que elas se apropriam de modos particulares do sistema mundial, reinventando seu esquema simbólico enquanto agentes interessados. (SHALINS, 1988). No entanto, a tentativa de integrar particularismos locais no sistema mundial através de 
organizações universais tem enfrentado dificuldades estruturais de diálogo com os Estados Nacionais.

O sistema mundial contemporâneo é determinado, portanto por uma lógica econômica indiferente às diferenças culturais. Ao expandir-se em uma extensão planetária, não apenas tornou evidente a ilusão da suposição de coincidência entre Estado e sociedade, ou a dificuldade de produzir leis que mantenham unidas sociedade e cultura, como também acelerou e multiplicou a movimentação de grupos culturais pelo sistema de modo a tornar cada vez mais remota a possibilidade de fazê-los corresponder a uma sociedade (MONTEIRO, 1996, p. 94-95).

A breve análise aqui realizada consistiu em um dos vários pontos de partida possíveis para reavaliar o discurso ocidental de liberdade e universalidade. A instrumentalização de práticas culturais através de leis que desrespeitam hábitos e crenças reitera que a cultura no contexto democrático globalizado é o meio para a conquista e perda de direitos bem como para a realocação e construção de identidades que escapam à identidade nacional.

Em síntese, presenciamos um terreno estreito de comunicabilidade entre identidades e culturas. Quando o Estado enquanto um mediador entre as unidades universalistas da lei e a diversidade de interesses culturais, ausenta-se do trabalho de transformar a desigualdade em diferença através de medidas legais e jurídicas, tomando partido por um interesse hegemônico, permite que parte da sociedade civil assista desamparada o cerceamento de suas formas de expressão em nome da liberdade, da igualdade e da fraternidade para o outros.

\section{REFERÊNCIAS}

ABU-LUGHOD, Lila. As mulheres muçulmanas precisam realmente de salvação? Reflexões antropológicas sobre o relativismo cultural e seus Outros. Rev. Estud. Fem. [online]. v. 20, n. 2, p. 451-470, 2012.

ALCORÃo Sagrado; versão portuguesa diretamente do árabe por Samir El Hayek, apresentação de S. E. Dr. Abdalla Abdel Chakur Kamel. São Paulo: Tangará, 1975.

COUTINHO, Carlos Nelson. Teoria e Debate. Edição 51, 2002. Disponível em: https://teoriaedebate.org.br/2002/07/02/carlos-nelson-coutinho/. Acesso em: 20 jan. 2019.

DOUGLAS, Mary; ISHERWOOD, Baron. O mundo dos bens: para uma antropologia do consumo. Rio de Janeiro: Editora UFRJ, 2009.

FERREIRA, Francirosy Campos Barbosa. Diálogos sobre o uso do véu (hijab): empoderamento, identidade e religiosidade. Perspectivas, São Paulo, v. 43, p. 183-198, jan./jun. 2013 
MONTERO, Paula. Cultura e Democracia no processo da globalização. Novos Estudos, CEBRAE n. ${ }^{\circ}$ 44, p.89-114, 1996.

ONU. Declaração Universal de Direitos Humanos, 1948. Disponível em:

http://www.dudh.org.br/declaracao/. Acesso em: 15 maio 2019.

PEW Research Center. 5 facts about the Muslim population in Europe, 2015. Disponível em: http://pewrsr.ch/2i3TIim. Acesso em: 15 maio 2019.

PINHEIRO, Paulo Sérgio. Os sessenta anos da Declaração Universal: atravessando um mar de contradições. Rev. int. direitos humanos, São Paulo, v. 5, n. 9, p. 76-87, dez. 2008.

SAHLINS, Marshall. Cosmologias do Capitalismo: O Setor Trans-Pacífico do 'Sistema Mundial. In: Anais [...] XVI Reunião Brasileira de Antropologia. Campinas, SP, 1988.

SAHLINS, Marshall. Cultura e razão prática. Rio de Janeiro, Zahar, 1979.

SAHLINS, Marshall. Ilhas de história. Rio de Janeiro: Zahar, 1990.

SEGATO, Rita Laura. Antropologia e direitos humanos: alteridade e ética no movimento de expansão dos direitos universais. Mana, Rio de Janeiro, v. 12, n. 1, p. 207-236, abr. 2006.

\section{Como referenciar este artigo}

SOUZA, Giovanna Lopes. Direitos humanos e cultura: a fragilidade do discurso universalista no contexto francês. Rev. Sem Aspas, Araraquara, v.7, n.2, p. 249-258, jul./dez., 2018. E-ISSN: 2358-4238. DOI: 10.29373/sas.v7i2.12141

Submetido em: $15 / 12 / 2018$

Aprovado em: 08/02/2019 